\title{
Electronic portfolios in the classroom: factors impacting teachers' integration of new technologies and new pedagogics
}

\author{
E.J. Meyer*, P.C. Abrami, A. Wade and R. Scherzer \\ This article presents the findings of a study on the use of an electronic portfolio (EP) in 16 \\ elementary classrooms across Canada. Using a mixed-methods approach, data were \\ collected to understand how teachers used EPs in their classrooms, to what extent they \\ integrated the EP into their practice, and the factors influencing their use. Using \\ expectancy theory, findings indicate that low implementers experienced significant \\ technical obstacles and/or were reluctant to change their established practices, whereas \\ high implementers reported feeling supported by their administration, experiencing growth \\ in their teaching practice, and using more pedagogical practices that support self-regulated \\ learning as a result of the scaffolding provided by the software.
}

Keywords: eportfolios; technology integration; construictivist pedagogy; student-centred learning; implementation fidelity

\section{Introduction}

Among the most interesting and exciting new developments in educational technologies are electronic portfolios (EPs). They can act as multimedia containers for students and teachers, as well as supporting student self-regulation and core educational competencies, especially literacy skills, According to Abrami and Barrett (2005), an EP is a digital container capable of storing visual and auditory content including text, images, video and sound. EPs are powerful learning tools not only because they organise content, but also because they are designed to support a variety of evidence-based pedagogical processes and assessment purposes.

The challenge of helping teachers to integrate new technologies and new pedagogics is well documented (Cuban, 1.993; Cuban, Kirkpatrick, \& Peck, 2001; Franklin, 2007; Hayes, 2007; Hernandez-Ramos, 2005; Judson, 2006; Schussler, Poole, Whitlock, \& Evertson, 2007; Wozney, Venkatesh, \& Abrami, 2006). In this article, we look carefully at the factors that influence the ways teachers used an EP and the extent to which teachers have integrated a particular electronic portfolio tool, ePEARL, and its pedagogical approach. This research did not just focus on the technical factors related to integrating new software into regular classroom practice, but also examined how certain technologies may be able to better support teachers' adoption of evidence-based pedagogical approaches.

\section{Theoretical framework Self-regulated learning}

According to Wade, Abrami, and Sclater (2005; see also Abrami, Savage, Wade,

\& Lopez, 2006), EPs are linked to students' ability to self-regulate their learning and to enhance meaningful learning of important educational skills and abilities, especially literacy skills. Self-regulated learners are individuals who are metacognitively, motivationally, and behaviourally active participants in their own learning (Zimmerman, 2000). A main feature of self-regulated learning (SRL) is metacognition. Meta-cognition refers to the awareness, knowledge, and control of cognition. The three processes that make up metacognitive selfregulation are planning, monitoring, and regulating. Proponents of socio-cognitive models 
emphasise that to develop effective self-regulated learning strategies, 'students need to be involved in complex meaningful tasks, choosing the products and processes that will be evaluated, modifying tasks and assessment criteria to attain an optimal challenge, obtaining support from peers, and evaluating their own work' (Perry, 1998, p. 716).

When students use portfolios, they assume more responsibility for their learning, better understand their strengths and limitations, and learn to set goals (Hiflyer \& Ley, 1996). One study with pre-service teachers noted that using electronic portfolios helped them 'engage in metacognitive activities while developing their philosophies' (Avraamidou \& Zembal-Saul, 2003, p. 437). In short, educators believe that portfolios allow students to think critically and become active, independent and self-regulated learners (Barrett, 2007; Perry, 1998; Zellers \& Mudrey, 2007). Our research on the use of ePEARL in the classroom provides evidence of student learning and literacy gains to support these beliefs (Abrami, Wade, Aslan, Bures \& Bentley, 2008; Meyer, Abrami, Wade, Aslan, Deault, 2010). There are limited studies that have examined the implementation and effectiveness of electronic portfolios in K-12 classrooms and this article aims to provide more insight into barriers and motivators for integrating such cross-curricular tools that have a broad range of potential applications in K-12 (Kindergarten - Grade 12 for children ages 5--18) classrooms.

\section{ePEARL}

ePEARL was designed by the [Centre for the Study of Learning and Performance (CSLP)] for use in early elementary (Level 1), late elementary (Level 2) and secondary (Level 3) schools and is available at no cost to schools. ePEARL's structure is based on Zimmerman's (2000) model of self-regulated learning and is designed to promote SRL skills through the creation of general and task-specific learning goals and strategies, monitoring of progress, and reflection on work completed, which is stimulated through peer, parent and teacher feedback on the portfolio or on a specific artefact. In Levels 2 and 3, ePEARL offers several features designed to promote the forethought phase of SRL through setting goals, identifying strategies and considering one's motivation to complete a task. It also provides students with a text editor for writing, an audio recorder for sound, and the capacity to attach up to three multimedia files. It is designed to stimulate students' reflection on their work through selecting, reflecting on, and getting feedback on the work they have completed. This explores the type of use of ePEAR.L and if teachers modified their pedagogical approaches to explicitly teach the SRL processes embedded in the software.

\section{Technology integration in classrooms}

Researchers have investigated the issue of integrating new technologies into the classroom and the generally low and traditional use of these new technologies (Cuban, 1993; Cuban et al., 2001; Franklin, 2007; Hayes, 2007; Hernandez-Ramos, 2005; Judson, 2006; Schussler et al., 2007; Wozney et al., 2006). Hennans, Tondeur, van Braak, and Valcke (2008) showed that teacher beliefs are significant determinants that can explain why teachers use computers in their teaching. Specifically, these researchers found that constructivist beliefs have a positive impact on the use of computers in the classroom and traditional, or teacher-centred, beliefs have a negative impact. Drent and Meelissen (2008) found that teachers who were identified as 'personal entrepreneurs' more consistently modelled innovative use of ICT. Personal entrepreneurship is defined as 'the amount of contacts a teacher educator keeps for his own professional development in the use of ICT' (p. 195). These researchers suggest that personal entrepreneurship can positively influence ICT attitude and competence and lead to perceived changes and innovative uses of ICT.

A third study (Mueller, Wood, Willoughby, Ross, \& Specht, 2008) identified differences between full implementers and limited implementers: positive teaching experiences with computers, teachers' comfort with computers, beliefs supporting the use of computers as an 
instructional tool, training, motivation, support and teaching efficacy. They also reported that elementary teachers who were integrating [CT in their classroom had higher scores on the WPI intrinsic motivation: challenge subscale. This suggests that these teachers are more intrinsically motivated and take on new projects for the challenges they present with the sole 'reward' being the satisfaction of completing a diflicult task. Finally, Hadjithoma and Karagiorgi (2009) reported that school-wide communities of implementation showed more successful implementation of ICTs in teaching than did schools that had 'enclaves' of high ICT use. They attributed this to ICT having a more 'normative value' in these schools, which they ascribed to local initiatives spearheaded by administrators and lead teachers in these schools. Although there has been extensive research on various technological innovations in schools, there are fewer studies that examine the pedagogical issues related to such educational change (Ginns, Norton, McRobbie, \& Davis, 2007; Harris, Mishra, \& Koehler, 2009; Koehler \& Mishra, 2005; Webb \& Cox, 2004). In Webb and Cox's (2004) review of pedagogy related to ICT, they underline the importance of teachers' beliefs in shaping pedagogical practices and emphasise in their conclusion that 'pedagogical practices associated with effective use of ICT ... are currently only achieved by the best teachers' and that supporting teachers in transforming their pedagogical practice is 'likely to be a very difficult and complex process' (p. 278).

\section{Expectancy theory}

Building on the research described above, our approach to exploring teachers' use of ePEARL in their classrooms is grounded in expectancy theory, which posits that teachers' perceived expectancy of success, combined with their perceived value and cost of technology use, can explain teachers' varying degrees of motivation to integrate technology in their classrooms. Wozney et al. (2006) explain that, according to this model, innovations are more likely to be adopted if the perceived value of the innovation and the likelihood (or expectancy) of success are high, as well as if these benefits outweigh the perceived costs of implementation. That is to say, teachers' decisions to use an innovation in the classroom relate to (a) how highly they value it; (b) how successful they expect to be; and (c) how highly they perceive the costs to be (p. 177). It is possible to at explanations from prior research into this theory. For example, the findings of Mueller et al. (2008) can be expressed in terms of expectancy, value, and cost factors. Therefore, in this study we examine how teachers implemented the ePEARL software and the SRL-related pedagogical practices in their classrooms and what factors influenced the degree and types of use, using expectancy theory as a lens, where possible.

\section{Methods}

This research is part of a multi-year Pan-Canadian study on the use of ePEARL in upper elementary classrooms. The results reported in this article are from 16 teachers from grades 4-6 classrooms in urban and rural English school boards in Quebec, Manitoba, and Alberta who voluntarily participated during the 2007-08 school year. All teachers were given at least a halfday of training on the use of ePEARL and follow-up support including lesson plans, job aids, instructional videos, an online discussion forum (in the form of a moderated wiki), as well as inclass observations and model lessons during the school year. The teachers were interviewed about their experiences with ePEARL. The sample was limited by the costs and complexities of training and data collection, which included interviews in different locations. Small differences among teachers are, therefore, not revealed in the quantitative data analyses.

We made numerous and varied efforts to encourage the widest possible adaptation and extensive use of ePEARL by teachers. Nevertheless, there were differences in implementation that are the subject of this investigation. The data for this article include: qualitative and quantitative analysis of student portfolios, Implementation Fidelity Questionnaire (IFQ), the Teaching and Learning Strategies Questionnaire (TLSQ), the Technology Integration Questionnaire (TIQ) (Wozney et al., 2006) and face-to-face semi-structured interviews (Teacher 
Exit Interview Protocol) with teachers which were transcribed and coded to identify factors that motivated or inhibited their use of ePEARL.

The IFQ was completed half-way through the research cycle (January/February) and again at the end of the school year (May/June). The IFQ included two main questions: 'In my class, over the last month, students worked with ePEARL: (0 hrs, 1-A hrs, 5--6 hrs, 9-12 hrs, 131hrs)' and 'When using ePEARL with my class, I would rate my access to technology and technical support as: (poor, acceptable, good, very good, excellent).' There were also two open-ended questions asking teachers to list the advantages and the challenges of using ePEARL.

The TLSQ is divided into five sections: Students' Learning Strategies, Approach to Teaching, Portfolio Use, Technology Experience and an open-ended section on ePEARL use and attitudes which is not described here. The TIQ is a series of closed-ended questions and groups items according to three different belief categories: the Expectancy of success, the perceived Value of technology use, and the perceived Cost of technology use. The data were thus organised and analysed according to these three categories by summing the corresponding items to arrive at a total score for each category (by teacher). Univariate analyses were performed on the post-test data to see if there were differences by implementation for each of the categories.

These multiple data sources provided a rich variety of information that gave researchers a broad understanding of how teachers used this software as well as the factors that shaped teachers' pedagogical applications of ePEARL. The focus of this article is on the levels of implementation and the factors that teachers reported as impacting how often and in what ways they integrated ePEARL into their teaching.

To determine levels of implementation, we used two measures: the IFQ, which was completed by the teachers at two points during the school year, and the Implementation Assessment Protocol, that included an analysis of student portfolios, as well as IFQ data to assign a code of low, medium, or high implementation to each teacher. Two members of the research team independently evaluated five randomly selected portfolios from each class and assigned a rating. The inter-rater agreement on the ratings was $100 \%$. These designations were made by considering the following items: average reported hours of usage each month, average number of artefacts stored in student portfolios, date range of use, and how ePEARL was used (for data storage only or use of SRL features) (see Table 1).

In order to better understand the reasons for teachers' varying degrees of implementation, we designed a Teacher Exit Interview Protocol. This 40-60-minute semi-structured interview guide was written with the intent of better understanding the factors that facilitate or inhibit the teachers' ability to integrate ePEARL into their classroom teaching, The interview addressed teachers' general impressions of the tool as well as the external and internal factors that shaped their use of it such as: administrative and technical support; access to computers; time management and scheduling issues; knowledge of portfolios and SRL; familiarity with ePEARL; and reasons for participating in the research. Questions addressed the teachers' expectations surrounding their use of ePEARL, what they found valuable, and what they saw as obstacles to using ePEARL with their students. An abridged copy of this interview guide is included as Appendix 1. 
Table 1. Implementation Assessment Protocol.

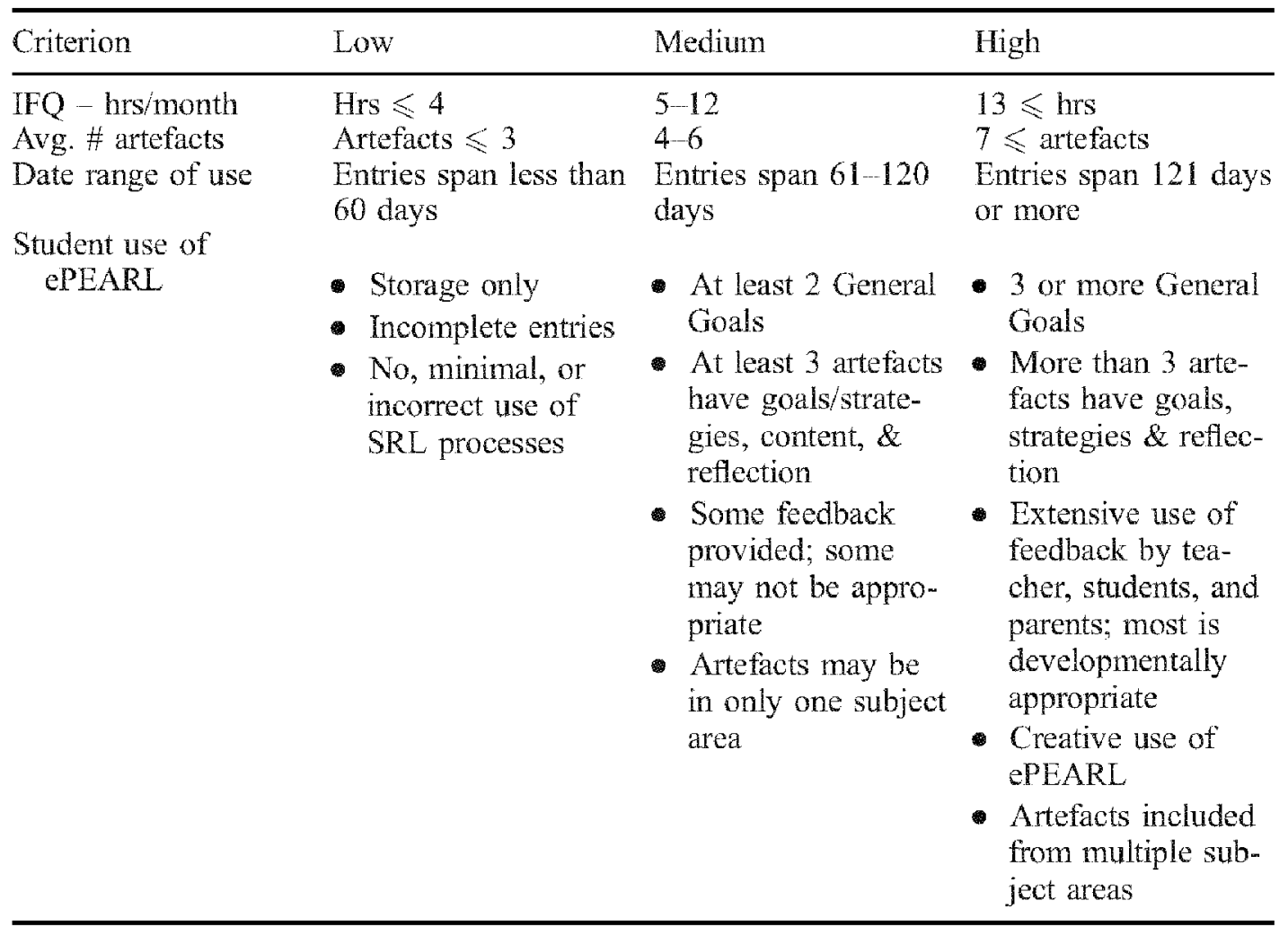

The teacher interviews were audio-recorded, transcribed, and then coded thematically by two members of the research team for analysis. We used the expectancyvalue-cost model of the TIQ to shape our preliminary understanding of the data. A coding tree was developed using some a priori codes based on key questions in the interviews, but additional codes were added during the analysis. Once all interviews had been preliminarily coded, the research team went back to do a deeper analysis of the expectancy, value, and cost categories to identify which factors might have acted as motivators for teachers to work more regularly with ePEARL and which factors may have acted as inhibitors or barriers for teachers to teach consistently with ePEARL. All the excerpts relating to expectations were coded based on the degree to which teachers articulated the belief that they would be successful, can do it' and the degree to which it would lead to a positive result, 'this will lead to a positive outcome'. For each value or cost item, a new sub-code was created that clearly described the issue addressed by the teacher. Examples of value sub-codes include: 'Student engagement/enthusiasm/interest', 'Access from home/anywhere' and 'positive impact on teaching'. Some of the cost sub-codes include: 'time consuming/scheduling difficulties', 'conflicting demands/one more thing' and 'computers freezing'. The results of this analysis are presented in the next section.

\section{Results Expectancy}

In 7 out of 16 classrooms (43\%), ePEARL was barely implemented. These classrooms were labelled as 'low' implementers. The portfolios in most of these classrooms had never been used, or were used quite minimally during the school year. Of the remaining nine classrooms, four were 'medium' implementers (25\%) and five were 'high' (31\%). The medium and high implementation classrooms were then combined for all analyses. The interview protocol asked only one question related to expectations and it was, 'What were your expectations about using ePEARL this year?' To code the interview data for expectancy-related comments, we used the following definition, 'teacher perceptions of the contingency between their use of the strategy 
and the desired outcomes; these include internal attributions (e.g. self-efficacy) and external attributions (e.g. student characteristics, classroom environment)' (Wozney et al., 2006, p. 178).

Four teachers expressed high positive expectations for the project: two low implementers, and two medium-high implementers. For example, one low implementer stated:

I thought it was an awesome piece, especially for communication with parents, and for kids to teach them to reflect on their stuff ... I thought, 'I'm going to learn this and become an expert at it, and so will the kids, and see the benefit of it.' So that was kind of an easy thing for me. (Teacher 1)

Four teachers expressed low expectations for the project: two low implementers and two medium-high implementers. An example of this is one high implementer who explained, 'I was expecting to have sort of something that would replace your paper portfolio' (Teacher 15). Many teachers had more detailed expectations of its functionalities but didn't express high expectations of positive impact. These other eight participants were coded as having moderate expectations: three low implementers and five medium-high implementers. An example of moderate expectations is illustrated by Teacher 10, a medium implementer, who said:

I liked that it was online, that they could go on and work on it at home and show parents at home, that the parents had a place where they could make a comment, and that involved the parents and the family in that whole aspect which is so important in education, getting them involved.

These data indicate that the 16 experimental teachers expressed a wide variety of expectations for their involvement in the project, and their expectations did not show a strong relationship with their levels of implementation.

problems, they chose not to invest any more time in a new project that wasn't receiving adequate support. It could also indicate that with a lack of support from administrators and school district personnel, these teachers didn't feel that the time invested in learning how to effectively teach with the tool and adapt their instructional practices accordingly would be valued by their superiors and chose to focus on other priorities instead.

We also conducted a cross-case analysis to further understand the reasons for varying levels of implementation (Gigante \& Firestone, 2008; Miles \& .flubennan, 1994). We compared each case across several variables including: TIQ scores, knowledge of SRL, ICT skills, technical issues, administrative support, and knowledge of ePEARL. This analysis showed that four of the seven low implementers worked in two schools. These four teachers (2, 4, 5, and 7) reported poor support for the project from their administrators and a second major obstacle. In one school the second obstacle was technical infrastructure problems which included: poorly maintained laptops, slow Internet speed, and regular problems with computers freezing and crashing. In the second school the teachers were asked to take over the project after the teacher who had been trained on the design and pedagogy of ePEARL left the school. These teachers were never trained properly and did not indicate feeling involved in the project. The other three low implementers $(1,3$, and 6) present interesting cases as two of them worked in schools that had a colleague who was a medium-high implementer, and the third (Teacher 6) did not give any indications in his interview that might explain his low use of ePEARL. However, Teachers 1 and 3 both expressed some concerns over instructional time lost to introduce ePEARL and to deal with technical problems, such as computers freezing or slow server speed, particularly since they taught grade 6 students who had to prepare for Provincial exams. The extreme importance of covering content in grades that have high-stakes tests was a deterrent to teachers spending time on integating a new student-centred tool into their classroom practice. This summary of the seven low implementers provides an overview of some of the key issues that may impede 
teachers' attempts to integrate a student-centred, cross-curricular tool such as ePEARL into their teaching.

\section{Value: motivators in implementation}

The data in Table 3 indicate that all teachers in this study experienced some barriers. However, it is clear that some teachers were able to overcome these perceived obstacles and persist in their teaching with this tool. The most common factors that teachers identified as valuable and may have been motivators for their use were:

(I) high level of student engagement/motivation/interest;

(2) teachers' personal enthusiasm for ePEARL;

(3) good pedagogical support to integrate the tool;

(4) the structure of the software that helped students plan and organise their work;

(5) accessibility of ePEARL from home or any Internet-connected computer;

(6) the customise feature which allowed students to take ownership over their portfolios.

Table 3 provides a summary of the most common value items mentioned in interviews. Value items were defined as 'the degree to which the teacher perceived

Table 3. Most frequent 'value' items identified by teachers using ePEARL.

\begin{tabular}{lccc}
\hline VALUE & Low & M-H & TOTAL, \\
\hline Student engagement/enthusiasmlinterest & 5 & 8 & 13 \\
Teacher enthusiasm for ePEARL & 5 & 8 & 13 \\
Good pedagogical support (videos, manual, lesson plans, class & 2 & 9 & 11 \\
$\quad$ visits, communications with research centre (CSLP)) & 3 & 8 & 11 \\
Planning/organising/structure & 4 & 7 & 11 \\
Customise feature & 2 & 8 & 10 \\
Access from home/anywhere & 2 & 7 & 9 \\
Administrative support & 4 & 6 & 10 \\
Student comfort with/enjoyment of technology & 2 & 7 & 9 \\
Parents liked it/involved & 1 & 7 & 8 \\
Shows growth/student development & 2 & 6 & 8 \\
Collaboration with colleagues & 2 & 6 & 8 \\
Good tech. support & 1 & 7 & 8 \\
Positive impact on teaching & 1 & 7 & 8 \\
User-friendly/kid-friendly & 3 & 5 & 8 \\
Way to integrate technology in class & 1 & 6 & 7 \\
Portability/portfolio for life & 1 & 6 & 7 \\
Positive impact on learning & 2 & 5 & 7 \\
Easier/better than paper portfolio & 3 & 4 & 7 \\
Student as expert'peer coaching & 2 & 5 & 7 \\
Student motivation & 0 & 6 & 6 \\
Personally interested in the project & & & \\
\hline
\end{tabular}

the innovation or its associated outcomes as worthwhile. These include benefits to the teacher (congruency with teaching philosophy, career advancement) and to the students (increased achievement, enhanced interpersonal skills)' (Wozney, Venkatesh, \& Abrami, 2006, 178).

The one value item that was mentioned by six of the medium-high implementers $(n=9)$ and none of the low implementers was that they had a personal interest in participating in the 
research project. This factor may indicate that a teacher's own level of personal investment and motivation in a project may be the most important factor influencing their desire to persist in the face of other challenges. It also may indicate that the pedagogical approach supported by ePEARL reinforces these teachers' existing pedagogical beliefs and classroom practices. This link is an important one noted in Webb and Cox's review of the literature (2004). Other important issues that medium-high implementers noted included: regular access to functioning computers, sufficient technical infrastructure to support the program (Internet speed, server size, speed, and data backup), and administrative support (provide funding to attend additional trainings, make requests to school board for hardware and technical support, show an ongoing interest in teachers' instructional uses of ePEARL). These are the factors that we have identified as necessary, but not sufficient, for any school to experience some level of success in working with ePEARL. In the two schools that had both a low and a medium-high implementer, the teachers who were the medium-high implementers (8 and 13) were the lead technology teachers in their schools. This may indicate that their added technical knowledge and the expectation from their administrators that they will train other colleagues on the program may have contributed to their higher levels of ePEARL use.

\section{Impacts on pedagogy}

As noted in Table 3, high implementation teachers also reported that ePEARL provided good pedagogical support (9/9) through the embedded help feature, instructional videos, sample lessons, and training provided. It also had a positive impact on transforming their teaching practice (7/9). Only two low implementation teachers mentioned the pedagogical supports they received through working with ePEARL and only one mentioned any positive impact on their teaching practice. It is possible that low implementers weren't able to experience this level of engagement with the tool if the other issues in their schools limited their use of and familiarity with ePEARL.

On the other hand, the medium and high implementers described how certain features in ePEARL, such as the place to provide a description of an assignment and the criteria, helped them make their expectations for their students more explicit and gave them a better awareness of the students' level of understanding of a task or an assignment. They integrated the SRLbased language of planning, doing and reflecting throughout classroom activities, and students in these classrooms showed increased levels of goal setting and reflecting on their work as compared to students in control classrooms (Meyer, Abrami, Wade, Asian \& Deault, 2010). One teacher noted:

I've used it as a guiding tool for my teaching this year. I love the learning cycle and it's helped me to become a better teacher because I've used the prompts to make sure I'm setting the criteria, making sure they know what makes a good job, and so we use it often, just out of context, not necessarily going online. But the language, and the whole process. (Teacher 9)

The fact that ePEARL provided clear step-by-step guidance that made explicit the steps of self-regulated learning was something that several teachers noted as beneficial. A second teacher who also appreciated the structure of ePEARL echoed this perspective:

I found that the way the template was set up, as far as getting the students to share what the criteria was for their work and to get them to reflect on their work -- that really channeled me in my teaching. I found you really had to force yourself in every lesson to think about 'Okay, we really need to think about the end in mind.' (Teacher 10)

This teacher's statement indicates how the design of the software supported her in being more conscious of how she was designing and presenting lessons and activities. Although it was clear that she understood the value of having clear objectives in mind, this statement indicates that she didn't always make it explicit for her students and ePEARL helped her to realise this and improve 
in this area. A third teacher mentioned how working, with ePEARL has changed her approach to teaching and helped her to be more deliberate in how she introduces new projects in her class.

That whole deliberate 'here are the steps of learning' -- I was never that deliberate. I made way too many assumptions of what they understood in that process. So that has very much changed the way I approach all of our things now. Like setting the goals, strategies, and criteria -- Yeah, you talk maybe about it, but it was never that deliberate and that's where the changes are coming. So yes, very much it's changed my approach. (Teacher 11)

A fourth teacher had a similar experience in being more conscious of how she taught and providing instructional support for students' development of self-regulated learning skills:

I like that because I think it helped me also focus a bit more on their setting goals. It really made me focus on that and verbalize it more. Like 1 said, sometimes I have a tendency to take things for granted, whereas here, I realize that, you know, we have to talk about certain aspects a little bit more if we really want to be ensured that the kids know exactly what direction they should be taking. And for them to be able to think about what the final result should look like, it gives them a good idea of what are they going to do to get there? That part I thought was good for me. Definitely.

(Teacher 15)

These excerpts illustrate that the design and features of ePEARL provided added value to teachers' instructional practice which resulted in positive impacts on student learning (Meyer, Abrami, Wade, Asian \& Deault, 2010).

The structures in ePEARL not only helped educators be more explicit and deliberate in how they presented content and projects to their classes, but it also offered a new way of teaching writing that sparked new interest in a seasoned educator. He described how working with ePEARL added 'a boost' to how he taught language arts:

The fact that I had ePEARL- available and the fact that I used it almost daily for a number of weeks gave myself a kind of a boost as to [how] I can actually accomplish things I thought were frustrating for me before. I was a math teacher in my mind, even though I taught everything from grade 1 to 12 . 1 just never thought that language arts [were] my strong suit. So the program actually got me excited about teaching writing for the first time in a long time. (Teacher 13)

These quotations demonstrate how the structure of the ePEARL software and the pedagogical support tools embedded in it helped teachers be more conscious of how they are presenting information and how their students understand what is being taught. It also helped more experienced educators reflect on how they taught language arts and offered a new perspective to instruction that inspired them and allowed them to be more creative. The teachers talked about the power of the portfolio and the ability to see evidence that a student has understood an assignment or a class activity. It also helped teachers to recognise when a student was lost or confused because s/he wasn't able to enter a description of the task or explain the criteria in his/her own words.

These reports by the teachers were confirmed by statistically significant increases in several SRI., activities reported on the TLSQ. In terms of their own approach to teaching, experimental teachers reported changes in the degree to which they explicitly taught the following skills, relative to the control teachers: monitoring progress towards goals $(\mathrm{F}(1,14)=$ 6.818, $p<0.05)$, modifying strategies $(F(1,14)=9.000, p<0.05)$, using peer feedback $(\mathrm{F}(1,14)=7.680, p<0.05)$ and attributing success to effort $(\mathrm{F}(1,14)=5.217, p<0.05)$. A more in-depth discussion of the learning gains from this study is presented in a separate article (Meyer, Abrami, Wade, Asian \& Deault, 2010).

\section{Comfort with technology}


Level of comfort or a predisposition to valuing technology did not seem to have an effect on levels of ePEARL use. The TIQ was used to compare the beliefs of teachers who participated in the ePEARL project but differed in their degree of implementation. There were no significant differences between the two implementation groups for Expectancy $\mathrm{F}(1,14)=.045$, $n s$; Value $\mathrm{F}(1,14)=.768$, ns; Cost $F(1,14)=5.81$, ns. Univariate analyses were also run by item; however there were no significant differences for any of the items. The null effects found here are potentially attributable to the small sample size for this data. But the analyses of the qualitative data revealed subtle differences among teacher expectancies, values and costs directly attributable to ePEARL, in particular, rather than technology, in general.

Teachers also completed a section of the TIQ titled 'Process of Integration', which asked them to rate the ways in which they use technology in their classrooms (Instructional, Communicative, Organisational, Analytic/Programming, Recreational, Expansive, Creative, Expressive, Evaluative, and Informative). Univariate analyses were run to compare teachers on these items. While teachers did not differ overall in their range of technology use $F(1,14)=$ $.605, p>.05$, teachers coded as medium/high reported that they were more likely to use technology for Creative $\mathrm{F}(1,14)=6.000, p<0.05$ and Evaluative $\mathrm{F}(1,14)=46.000, p<0.05$ purposes in their classroom as compared with classrooms coded as low irn.plementers. There was also a marginally significant tendency towards the use of technology for Informative purposes $\mathrm{F}(1,14)=4.500, p=0.055$ in medium/high implementation classrooms.

Finally, a score was assigned to each teacher according to a formula developed by the authors of the TIQ (Wozney et al., 2006). Teachers in the medium/high and low implementation groups did not differ overall in terms of the total TIQ score assigned to each teacher $\mathrm{F}(1,14)=.037$, pis). All teachers spoke of the additional time required to learn a new tool and to plan how to integrate new instructional approaches in their classrooms; however, medium and high implementation teachers spoke about how the pedagogical benefits of this additional effort outweighed the costs of this increased preparation time whereas low implementation teachers did not perceive that it was worth the added time investment.

\section{Discussion}

In this article we explored the teachers' expectations for and experiences with the electronic portfolio that were motivators for, or barriers to, their use in order to better understand the challenges facing educators, schools and school districts that are moving towards integrating new technologies and evidence-based instructional practices in their curricula. While our prior research (Meyer, Abrami, Wade, Asian \& Deault, 2010) showed whether ePEARL promotes selfregulation and literacy skills in high implementation classrooms, the current investigation explores why these increases occur from the teachers' point of view as well as the conditions necessary for successful implementation.

It is important to have an in-depth understanding of the realities facing teachers in order to better anticipate their needs and provide pedagogical and technical supports that will give them the resources they need to work through barriers when they arise. In terms of ePEARL, it was clear that teachers who we:re personally committed to learning how to use the new technology, saw the pedagogical benefits, and who had administrators and technical personnel who were willing to actively promote these initiatives were able to m.ore regularly and consistently integrate ePEARL in their teaching. On the other hand, teachers who did not personally volunteer for the project, or felt as if their administrators and technology personnel were not providing adequate support, were less likely to persist in the face of technical and time constraints. This echoes the findings of earlier studies on technology integration (Drent \& Meelissen, 2008; Hadjithoma \& Karagiorgi, 2009; Mueller et al., 2008).

No clear relationship emerged between high positive expectations and high implementation of ePEARL. This is not consistent with the conclusions reported by Wozney et al. (2006) who reported that 'factors related to the expectancy of success were 
the most predictive of computers use' (p. 195). That is to say that some low implementers had expressed high expectations and some high implementers had expressed low expectations. One possible explanation for this is that moderate expectations may be more motivating when integrating a new approach in one's teaching. If one has high expectations and then experiences some barriers or difficulties, it may be disappointing and demotivating; whereas, if one has moderate expectations and begins to see positive results that exceed expectations, this may be more motivating to continue to engage in the project. For example, one teacher explained, 'I think our expectations were that [the students] would be further [along] than what they were when they arrived, and so that was our naivete, I think ... we had expectations that weren't there for our class and the kids, so that part was a bit of a curve for us' (Teacher 16).

As mentioned earlier, all the teachers in this research had the opportunity to receive training and follow-up support from the [Centre for the Study of Learning and Performance (CSLP)], identified earlier in the methods section. These forms of support were identified as important by Mueller et al. (2008), yet we failed to achieve a uniformly high level of implementation fidelity and strength. While some of the barriers to effective implementation were described as external to the teacher (i.e. technical barriers), other factors were internal to the teacher (e.g. value of using ePEARL). Medium and high implementers of ePEARL reported that it positively impacted on their teaching practice and provided them with valuable pedagogical supports to integrate SRL and portfolio pedagogy into their classrooms. These data are encouraging as this was part of the intended design of the software. It not only provides structure and support for students as they develop selfregulated learning skills, but it also provides valuable information and resources to teachers who are working to integrate these student-centred pedagogies in their teaching practice. The findings from this research can offer teacher educators, educational leaders and researchers valuable insight into what kinds of support teachers need to implement new technologies in the classroom. A strong link to a clear pedagogical benefit -- such as improving students' SRL skills --- may help move educators past perceived barriers by providing them with strong positive motivators related to learning outcomes. This research also demonstrates the potential long-term benefits of adopting an electronic portfolio such as ePEARL on a larger scale in new initiatives to promote student-centred learning and reflective teaching practices.

While it is technically simple to implement, not all applications of technology for learning require the degree of pedagogical change as ePEARL requires. This sets it apart from tools that, for example, facilitate the acquisition of basic content or simple routines, sometimes referred to as declarative knowledge. Requiring teachers and their students to mutually engage in classroom practices that support self-regulation requires more time, effort, expectations of success and valuing of outcomes linked to procedural knowledge. This study of a small sample of teachers begins to explore the nature of these challenges and lays the groundwork for future research on deeper pedagogical change facilitated by technology.

As a result of this study we offer several recommendations to researchers and school leaders who are working to integrate educational technologies such as ePEARL into K-12 classrooms. First, it is essential to ensure that the classrooms and schools have sufficient technical infrastructure. In the case of ePEARL and other web-based applications, this includes having sufficient bandwidth, Internet access points (either Ethernet ports or wireless hubs), and a server that can handle the load of multiple simultaneous users. In addition to the technical infrastructure, teachers and students must have consistent access (at least one hour per week) to functioning computers that are regularly maintained by technical support professionals. Third, teachers must feel that there is positive support from the administration to invest the time in learning to teach with ePEARL, or any new tool that requires adaptations to traditional instructional practices. This means that principals and school boards need to work to: 1) ensure that the required technologies are available and functioning properly, 2) provide 
time and funding for professional development and collegial collaboration, and 3) clearly communicate that using ePEARL is a priority.

How else might we convert teachers from believing they cannot use technology into believing they must use technology for learning? We offer several possible courses of action. First, teacher training needs to focus more on why using educational technology such as ePEARL is important and appropriate rather than only how to use it. Presenting theory and research in an understandable and compelling fashion may help achieve this objective. At the same time, effectiveness concerns may need to be balanced with teacher efficiency concerns. ePEARL, for example, is not a technically difficult tool to use, but it is pedagogically challenging. Its focus on student-centred learning means that teachers need to accept classroom practices that go beyond didactic forms of instruction.

Second, testimonials, demonstrations, and collaborative support from successful teachers may help convince non-implementers to develop positive beliefs. The dilemma is how best to provide support when most consultants and technical support personnel are not consistently present in a school community, therefore schools may benefit from finding ways to provide more internal, local support by designating lead teachers or having principals act as pedagogical leaders as well as administrative ones. Third, while we hope teachers come to develop beliefs consistent with the effective uses of technology for learning, we also appreciate that intrinsic reasons may be insufficient for some. The last suggestion is to provide external encouragement for teachers to adapt an innovation and provide a culture that values experimentation, improvement, and evidence-based practices.

Educational technologies are here to stay. With increasing demands on teachers to integrate new technologies into their classroom practices and adjust their pedagogics to support the flexibility and individuality offered by these technologies, it is essential that we understand the factors that shape how teachers integrate new technologies and the associated instructional practices into their teaching. This study offers a rich and detailed understanding of the multiple factors that influence how well and to what degree teachers implement an electronic portfolio that supports self-regulated learning in constructivist classrooms. This research also documented the positive impacts ePEARL can have on teachers' pedagogical practices by scaffolding teachers through the software and embedded support, ePEARL encourages teachers to adopt more student-centred approaches to teaching and to spend more time in explicitly teaching self-regulated learning skills (such as goal setting, monitoring, and reflecting).

\section{Notes on contributors}

Elizabeth J. Meyer, PhD is an Assistant Professor in the School of Education at California Polytechnic State University in San Luis Obispo, California and is a Collaborator at the Centre for the Study of Learning and Perfonnance at Concordia University in Montreal, Quebec, Canada.

Philip C. Abrami, PhD is a Professor in the Department of Education and the Director of the Centre for the Study of Learning and Performance at Concordia University in Montreal, Quebec, Canada.

Anne C. Wade, MLIS is Manager and information Specialist at the Centre for the Study of Learning and Performance at Concordia University in Montreal, Quebec, Canada.

Rachel Scherzer, MA completed her Masters Degree in the Department of Education at Concordia University in Montreal, Quebec, Canada and is a student member of the Centre for the Study of Learning and Performance at Concordia University in Montreal, Quebec, Canada.

\section{References}

Abrami, P.C., \& Barrett, H. (2005). Directions for research and development on electronic portfolios. Canadian Journal of Learning and Technology, 31, 1-15.

Abrami, P.C., Savage, R., Wade, A., Hipps, G., \& Lopez, M. (2006). Using technology to assist children learning to read and write. In T. Willoughby \& E. Wood (Eds.), Children s learning in a digital world, 129172. Oxford: Blackwell Publishing. 
Abrami, P.C., Wade, A., Asian, 0., Bures, E.M., \& Bentley, C. 2008. Encouraging self-regulated learning through electronic portfolios. Canadian Journal of Learning and Technology/La Revue Canadienne de L'Apprentissage Et De La Technologic, 34(3) from http:// www.cjIt.ca/index.php/cjltlissue/view/66.

Avraamidou, L., \& Zembal-Saul, C. (2003). Exploring the influence of web-based portfolio development on learning to teach elementary science. Journal of Technology and Teacher Education, 11, 415-442.

Barrett, H.C. (2007). Researching electronic portfolios and learner engagement: The REFLECT initiative. Journal of Adolescent and Adult Literacy, 50, 436-449.

Cuban, L. (1993). Computers meet classroom: Classroom wins. Teachers College Record, 95, 185-210.

Cuban, L., Kirkpatrick, H., \& Peck, C. (2001). High access and low use of technologies in high school classrooms: Explaining an apparent paradox. American Educational Research Journal, 38, 813-834.

Drent, M., \& Meelissen, M. (2008). Which factors obstruct or stimulate teacher educators to use ICT innovatively? Computers \& Education, 51, 187--199.

Franklin, C. (2007). Factors that influence elementary teachers' use of computers. Journal of Technology and Teacher Education, 15, 267-293.

Gigante, N.A., \& Firestone, W.A. (2008). Administrative support and. teacher leadership in schools implementing reform. Journal of Educational Administration, 46, 302-331.

Ginns, I.S., Norton, S.J., McRobbie, C.J., \& Davis, R.S. (2007). Can twenty years of technology education assist 'grass roots' syllabus implementation? International Journal of Technology and Design Education, 17, 197--215.

Ha.djithoma, C., \& Karagiorgi, Y. (2009). The use of ICT in primary schools within emerging communities of implementation. Computers \& Education; 52, 83-91.

Harris, J., Mishra, P., \& Koehler, M. (2009). Teachers' technological pedagogical content knowledge and learning activity types: Curriculum-based technology integration reframed. Journal of Research on Technology in Education, 41, 393-416.

Hayes, D. (2007). ICT and learning: Lessons from Australian classrooms. Computers \& Education, 49, 385395.

Hermans, R., Tondeur, J., van Braak, J., \& Valcke, M. (2008). The impact of primary school teachers' educational beliefs on the classroom use of computers. Computers \& Education, 51, 1499-1509.

Hernandez-Ramos, P. (2005). If not here, where? Understanding teachers' use of technology in Silicon Valley schools. Journal of Research on Technology in Education, 38, 39-64. Hillyer,

J., \& Ley, T.C. (1996). Portfolios and second graders' self-assessments of their development as writers. Reading Improvement, 133, 148-159.

Judson, E. (2006). How teachers integrate technology and their beliefs about learning: Is there a connection? Journal of Technology and Teacher Education, 14, 581-597.

Koehler, M.J., \& Mishra, P. (2005). What happens when teachers design educational technology? The development of technological pedagogical content knowledge. Journal of Educational Computing Research, 32, 131-152.

Meyer, E.J., Abrami, P.C., Wade, A., Asian, 0. \& Deault, L. (2010). Improving literacy and inetacognition with electronic portfolios; Teaching and Learning with ePEARL. Computers \& Education, 55(1), 84-91.

Miles, M.B., \& Hubennan, A.M. (1994). Qualitative data analysis: An expanded source-book. Thousand Oaks, CA: Sage Publications.

Mueller, J., Wood, E., Willoughby, T., Ross, C., \& Specht,1. (2008). Identifying discriminating variables between teachers who fully integrate computers and teachers with limited integration. Computers \& Education, 51, 1523--1537.

Perry, N.E. (1998). Young children's self-regulated learning and contexts that support it. Journal of Educational Psychology, 90, 715-729.

Schussler, D., Poole, I., Whitlock, T., \& Evertson, C. (2007). Layers and links: Learning to juggle 'one more thing' in the classroom. Teaching and Teacher Education, 23, 572585

Wade, A., Abrami, P.C., \& Sclater, J. (2005). An electronic portfolio for learning. Canadian Journal of Learning and Technology, 31, 33-50.

Webb, M., \& Cox, M. (2004). A review of pedagogy related to information and communications technology. Technology, Pedagogy and Education, 13, 235-286.

Wozney, L., Venkatesh, V., \& Abrami, P. (2006). Implementing computer technologies: Teachers' perceptions and practices. Journal of Technology and Teacher Education, 14, 173-207.

Zellers, M., \& Mudrey, R. (2007). Electronic portfolios and metacognition: A phenomenological examination of the implementation of e-Portfolios from the instructors' perspective. International Journal of Instructional Media, 34, 419-430.

Zimmerman, B.J. (2000). Attaining self-regulation: A social cognitive perspective. In M. Boekaerts \& RR. Pintrich (Eds.), Handbook of selflregulation (pp. 13-39). New York: Academic Press. 
TEACHER EXIT INTERVIEW PROTOCOL (abridged

version 1 br publication)

\section{Intro (10 minutes)}

(1) If you were to sum up your use of ePEARL with your students this year in a few words, how would you describe it?

(2) What were your expectations about using ePEARL this year?

(3) What did you find was most valuable about using ePEARL?

(4) What did you find the most frustrating or difficult?

\section{External — Formal (5 minutes)}

(5) flow did you use ePEARL in your class this year?

(6) Tell me about ePEARL and time management and the scheduling aspects of the school:

(7) What did you like about the software? What did you dislike?

External — Informal (5 minutes)

(8) Please tell us about your administrators and their involvement in ePEARL.

(9) Can you talk about other professional support you've had for ePEARL this year? (consultants [such as REC1T or ELA], attending workshops and trainings)

(10) Can you talk a bit about other teachers in your school and their use of or perceptions towards ePEARL?

(11) Tell us about the attitudes of your students towards ePEARL.

(12) Parents' attitudes?

\section{Internal — Formal (10 minutes)}

(13) Could you talk a little bit about your approach to teaching? (or: How would you describe your teaching philosophy?)

(14) Can you talk about your level of comfort and understanding of ePEARL?

(a) Set general goals

(b) Set task goals

(c) Identify strategies

(d) Reflect on their work

(a) Is it important to you that your students understand these processes?

(b) How do you feel about teaching SRL processes?

(c) In what ways do you teach it? (explicitly, integrated, mixed)

\section{Internal — Informal (5 minutes)}


(16) How do you feel about using ePortfolios in general? (Helpful? Confusing? Time consuming? Add to students' learning? Take away time from other activities?)

(17) Did ePEARL influence your teaching in any way?

(18) Describe your students' understandings of Self-Regulated Learning (SRL) processes.

\section{Conclusion (5 minutes)}

(19) Why did you decide to participate in this study?

(20) Is there anything else that you would like to add about using ePEARL with your students this year?

(15) How did you teach your students to: 